\title{
A Study on Drug Utilization Pattern and Cardiovascular Disease Prevalence in a Tertiary Care Hospital
}

\author{
M. Rangapriya*, Merin Kurian, Nandhini P.M, Merlin K Reji, Nancy Sinha \\ Dept.of Pharmacy Practice, Swamy Vivekanandha College of Pharmacy, Elayampalayam, Namakkal, Tamilnadu, India. \\ *Corresponding author's E-mail: priyanarayan97@gmail.com
}

Received: 21-02-2021; Revised: 24-04-2021; Accepted: 30-04-2021; Published on: 15-05-2021.

\begin{abstract}
The aim of the present study was to evaluate the drug utilization pattern and prevalence of cardiovascular diseases in the cardiology department in a tertiary care hospital. The study was a retrospective Observational study, carried out in cardiology department at Viveka nandha Medical Care Hospital, Elayampalayam, Tiruchengode for a period of six months from December 2020 - June 2020. 200 subjects were included in our study. The data like demographic details of patients, indication, disease prevalence, comorbidities and prescribing pattern were collected. In our study out of 100 patients, $65 \%$ were male and $35 \%$ were female. The cardiac disease was highest in patients of the age group 61-70 years. The most common cardiovascular disease treated was myocardial infarction $(31 \%)$ and the most common associated comorbidity was hypertension. The top three prescribed cardiovascular drugs were aspirin (15.5\%), atorvastatin (13.7\%) and clopidogrel (11.44\%). The presence of polypharmacy leads to the occurrence of potential DDIs which increase the risk in patients with cardiovascular diseases. The present study will provide feedback to the health care professionals to achieve rational drug therapy.
\end{abstract}

Keywords: Drug utilization pattern, Rational drug therapy, Polypharmacy, Cardiovascular disease.

QUICK RESPONSE CODE $\rightarrow$

DOI:

10.47583/ijpsrr.2021.v68i01.007

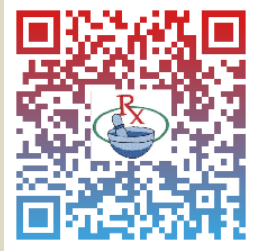

DOI link: $\underline{\text { http://dx.doi.org/10.47583/ijpsrr.2021.v68i01.007 }}$

\section{INTRODUCTION}

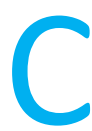

ardiovascular diseases are the leading cause of death in the world. ${ }^{1}$ In India, drug utilization study demonstrates the existence of a wide range of cardiovascular drugs for prophylaxis and therapeutic use. ${ }^{1}$, ${ }^{2}$ Drug utilization study is a solid investigational measure to estimate the current model of drug usage and the relevance of prescriptions. ${ }^{3}$ DUS evaluates the safety and rationality of the drug therapy. It has a positive impact on the prescribing physician and improves the prescribing pattern of the physician and assist them in changing the treatment strategies whenever required, identify and make an appropriate decision for safe and cost-effective therapy. ${ }^{4}$

Multiple drugs are often required due to several comorbidities which turn out to be a barrier to get appropriate therapy. Drug interactions may occur as a result of polypharmacy, complicating the diagnosis and leading to other undesirable outcomes. ${ }^{5}$ Comorbidities related to cardiovascular diseases include diabetes mellitus, obesity, COPD, HTN, CAD, CVA, arrhythmia, OA, thyroid disease, hyperlipidaemia, renal dysfunction and anemia.
Drug-drug interaction (DDI) arises mostly whenever a patient receives more than one drug and chances in increase with number of drugs taken. There are a variety of DDIs that can cause toxicity, alteration of the desired therapeutic effects or even result in a life-threatening condition. Polypharmacy used to treat the patient's comorbidities, is one of the risk factors for drug-drug interactions. ${ }^{6}$ Drug-drug interactions is the one of major cause of adverse drug reactions (ADR) resulting in hospital and emergency department. ${ }^{7}$ Polypharmacy plays a key role in drug interaction and which leads to further complications. $^{8}$

\section{MATERIALS AND METHODS}

The study was performed to assess the prevalence of cardiovascular diseases, drug utilization Pattern and clinical comorbidity interaction in patient with cardiac disease. The current study was a retrospective observational study which was done in cardiology department at Vivekanandha Medical Care Hospital, Elayampalayam, Tiruchengode. Both male and female inpatients with CVDs and age more than 20 years were included in our study. Data and records with incomplete information, Pregnant women were excluded in our study.

\section{Study procedure}

Case reports of 100 patients were randomly selected for the study as per the inclusion and exclusion criteria. The demographic data, indication for drug use, comorbidities present, duration of hospital stay, number of medications, names of individual medications, fixed dose combination (if any), route of administration, dosing schedule, duration of treatment and average number of the medications 
prescribed per encounter were collected from the respective patient case files and entered into the specifically designed data entry form.

\section{RESULTS}

\section{Gender wise distribution of cardiac diseases}

Figure -1 shows that out of 100 patients, 65 (65\%) were male and 35 (35\%) were female. Male patients had a high incidence of CVDs as compared to female patients.

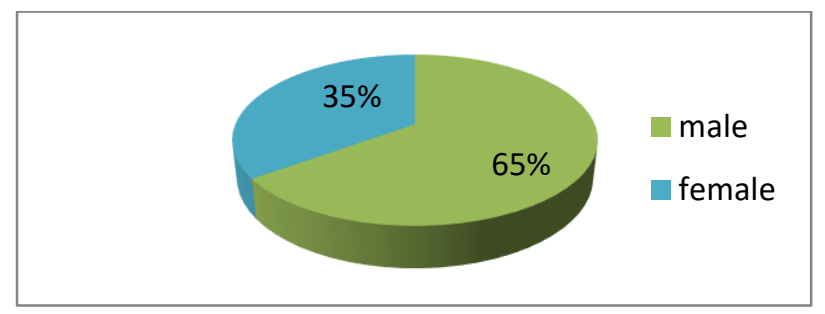

Figure 1: Gender wise distribution of cardiac disease

\section{Age wise distribution of cardiac diseases}

Figure- 2 shows that the cardiovascular incidence was highest in patients who belonged to the age group 61-70 years. Out of 100 patients, 30 (30\%) belonged to $61-70$ years. The incidence of cardiovascular emergencies in male patient (24 patients) in age group 61-70 years was found significantly higher than female patient ( 6 patients) in age group 61-70 years.

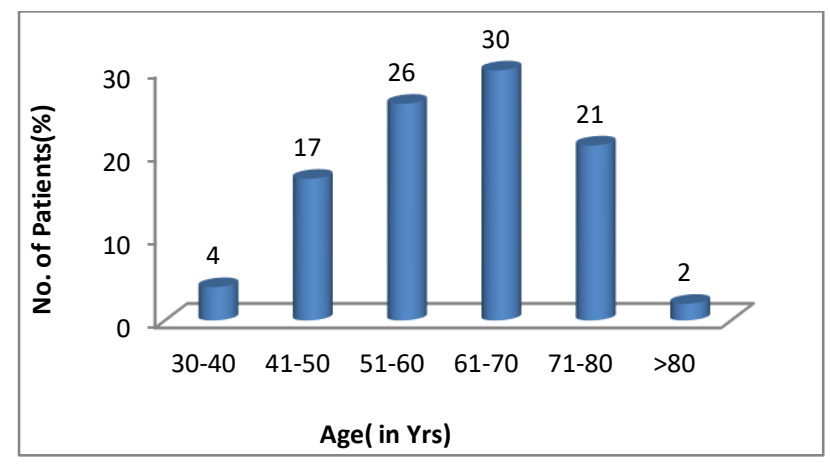

Figure 2: Age wise distribution of cardiac disease

\section{Common cardiovascular diseases treated}

Figure-3 shows that the most common cardiovascular disease treated in patients was myocardial infarction in 31patients (31\%) followed by angina in 29 (29\%), CAD in 27 $(27 \%)$ and arrhythmia in17 patients $(17 \%)$.

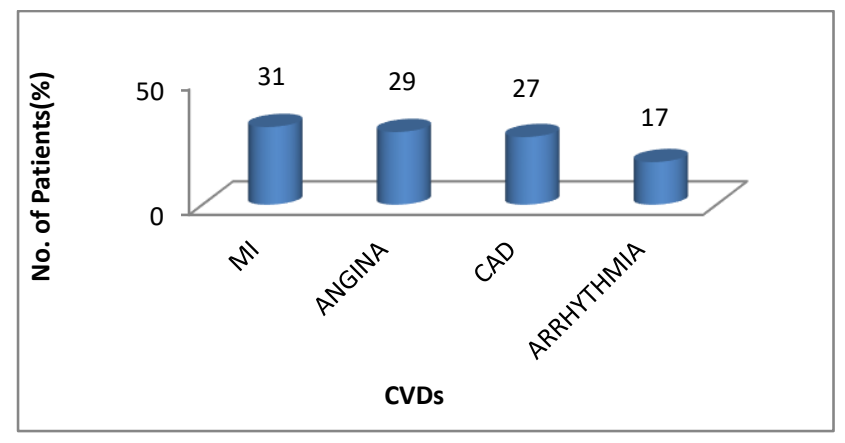

Figure 3: Commonly treated cardiovascular diseases

\section{Comorbidities associated with cardiovascular disease}

In our study, the most commonly associated comorbidity was hypertension (45\%), followed by DM (33\%), COPD (7\%), CAD (5\%), Hyperlipidemia (5\%) and ARF (5\%) shown in Table 1.

Table 1: Common comorbidities associated with CVDs $(\mathrm{N}=100)$

\begin{tabular}{|c|c|}
\hline COMORBIDITY & NUMBER OF PATIENTS \\
\hline HTN & 45 \\
\hline DM & 33 \\
\hline CAD & 5 \\
\hline HYPERLIPIDEMIA & 5 \\
\hline COPD & 7 \\
\hline ARF & 5 \\
\hline
\end{tabular}

\section{Number of co-morbidities associated with cvds}

Out of 100 prescriptions, about 44 prescriptions (44\%) had two co-morbidities followed by 43 prescriptions (43\%) with one co-morbidity, 8 (8\%) prescriptions had three comorbidities and 5 (5\%) prescriptions had four comorbidities during the hospital admission (Table 2).

Table 2: Number of comorbidities associated with CVDs

\begin{tabular}{|c|c|}
\hline NO. OF COMORBIDIDY & NO. OF PRESCRIPTIONS \\
\hline ONE & 43 \\
\hline TWO & 44 \\
\hline THREE & 8 \\
\hline FOUR & 5 \\
\hline TOTAL & 100 \\
\hline
\end{tabular}

\section{Duration of hospital stay}

The duration of hospital stay varied according to the related conditions. In our study, 54 patients (54\%) were admitted for less than 7 days in hospital, 30 patients (30\%) for 7 days and 16 patients (16\%) spent more than 7 days in hospital (Figure 4).

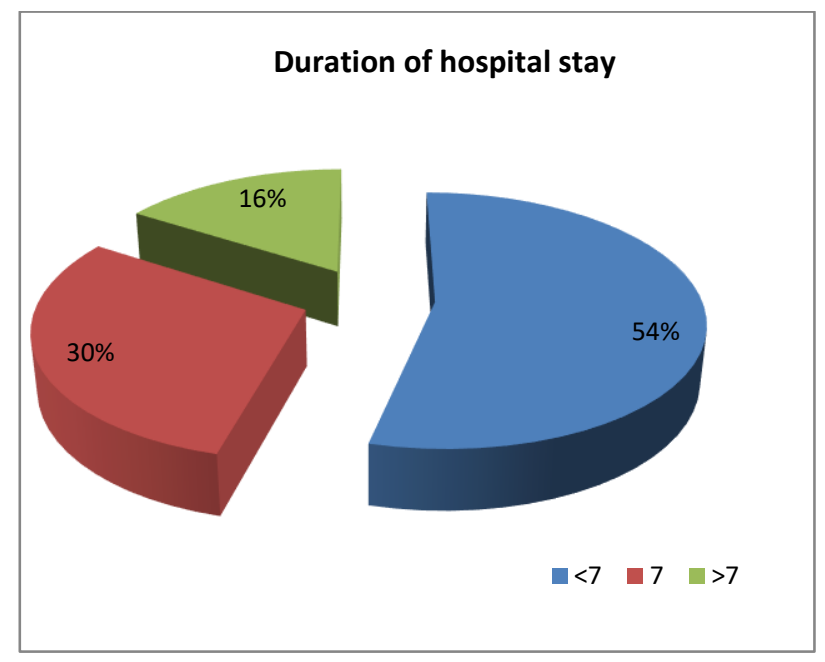

Figure 4: Duration of hospital stay 


\section{Class wise utilization of cardiovascular drugs}

Out of the 437 cardio vascular drug prescriptions, antiplatelets (31.80\%) were the most commonly prescribed class followed by antihyperlipidemic (15.5\%), anticoagulants $(11.2 \%)$, vasodilators $(9.15 \%)$, calcium channel blockers $(9.15 \%)$, diuretics $(8 \%)$, beta blockers (6.86\%) (Table 3 and Figure 5).

Table 3: Class wise utilization of cardiovascular drugs

\begin{tabular}{|c|c|c|c|}
\hline S. No. & Drug class & Frequency of prescription & Percentage (\%) \\
\hline 1. & Antiplatelets & 139 & 31.80 \\
\hline 2. & Anti-hyperlipidemic & 68 & 15.5 \\
\hline 3. & Anticoagulants & 49 & 11.21 \\
\hline 4. & Vasodilators & 40 & 9.15 \\
\hline 5. & Calcium channel blocker & 40 & 9.15 \\
\hline 6. & Diuretics & 35 & 8.0 \\
\hline 7 & Beta blocker & 30 & 6.86 \\
\hline 8. & Ace inhibitors & 17 & 3.2 \\
\hline 10. & Cardiac glycosides & 7 & 1.6 \\
\hline 11. & Arb blockers & 10 & 2.28 \\
\hline
\end{tabular}

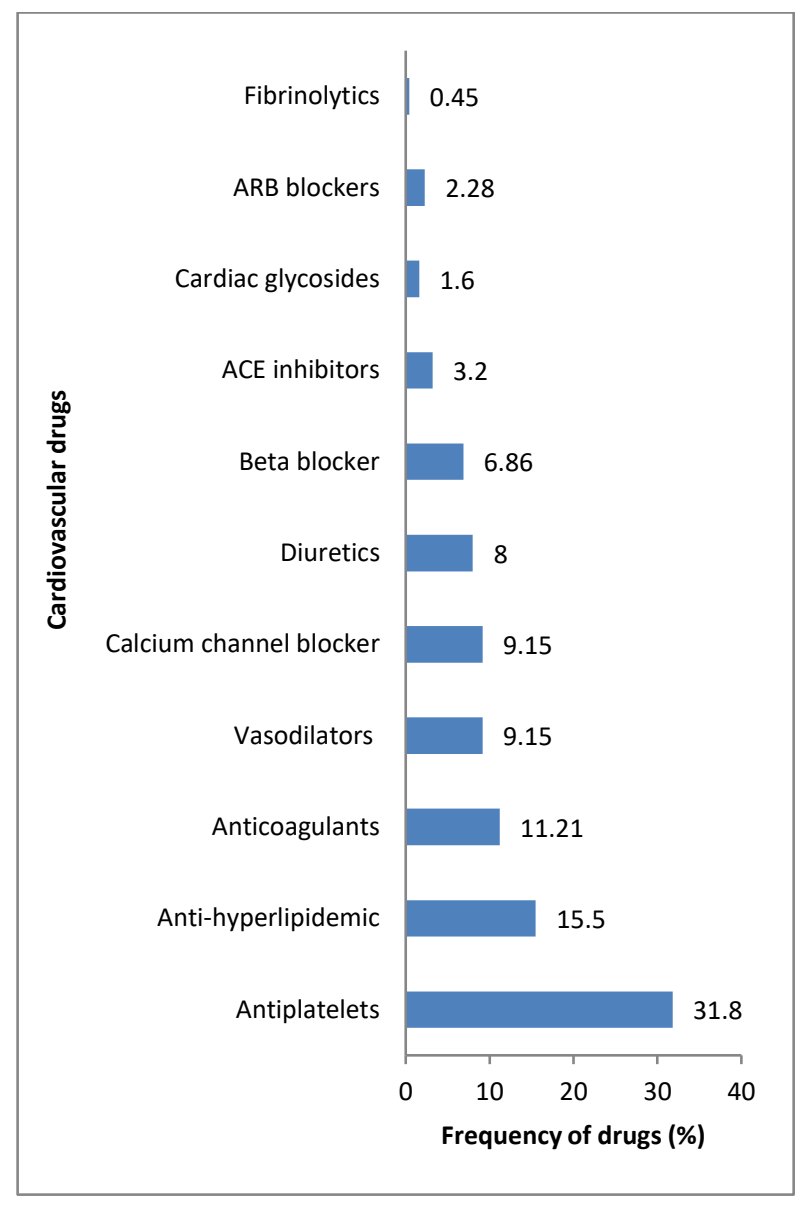

Figure 5: Class wise utilization of cardiovascular drugs

\section{Utilization pattern of cardiovascular drugs}

Table-4 shows that out of the 100 prescriptions, 29 cardiovascular drugs were prescribed frequently among which the top three prescribed drugs were aspirin (15.5\%), atorvastatin (13.7\%) and clopidogrel (11.44\%). The most

preferred class of antihypertensive drugs was diuretics, beta blockers, calcium channel blockers, ACE inhibitors and ARBs. Furosemide (5.72\%), amlodipine (4.57\%), metoprolol (4.57\%) and ramipril (3.2\%) were the commonly prescribed antihypertensive drugs. The combination of aspirin and clopidogrel were also prescribed for the synergistic activity. Cardiac glycoside like digoxin was prescribed to only $1.6 \%$ patients. Most commonly prescribed vasodilators were isosorbidedinitrate (8.23\%) and nitroglycerin (5.03\%). Anticoagulants such as heparin (4.34\%), fondaparinux (3.20\%) and enoxaparin sodium (2.74\%) were also prescribed commonly (Figure 6).

Table 4: Utilization pattern of cardiovascular drugs

\begin{tabular}{|l|l|c|c|}
\hline S. No. & Drug name & $\begin{array}{c}\text { No. of } \\
\text { patients } \\
\text { prescribed }\end{array}$ & $\begin{array}{c}\text { Percentage } \\
\text { (\%) }\end{array}$ \\
\hline 1. & Metoprolol & 20 & 4.57 \\
\hline 2. & Carvedilol & 2 & 0.45 \\
\hline 3. & Atenolol & 4 & 0.91 \\
\hline 4. & Bisoprolol & 4 & 0.91 \\
\hline 5. & Atorvastatin & 60 & 13.7 \\
\hline 6. & Rosuvastatin & 8 & 1.83 \\
\hline 7. & Clopidogrel & 50 & 11.44 \\
\hline 8. & Aspirin & 68 & 15.5 \\
\hline 9. & Aspirin+ & 17 & 3.89 \\
\hline 10. & clopidogrel & 12 & 2.74 \\
\hline 11. & Streptokinase & 2 & 0.45 \\
\hline 12. & Warfarin & 4 & 0.91 \\
\hline 13. & Heparin & 19 & 4.34 \\
\hline
\end{tabular}




\begin{tabular}{|l|c|c|c|}
\hline 14. & Enoxaparin sodium & 12 & 2.74 \\
\hline 15. & Fondaparinux & 14 & 3.20 \\
\hline 16. & Nitroglycerin & 22 & 5.03 \\
\hline 17. & Isosorbidedinitrate & 36 & 8.23 \\
\hline 18. & Glyceryldinitrate & 2 & 0.45 \\
\hline 19. & Ramipril & 17 & 3.2 \\
\hline 20. & Digoxin & 7 & 1.6 \\
\hline 21. & Nicorandil & 8 & 1.83 \\
\hline 22. & Amlodipine & 20 & 4.57 \\
\hline 23. & Clinidipine & 5 & 1.14 \\
\hline 24. & Diltiazem & 2 & 0.45 \\
\hline 25. & Amiodarone & 2 & 0.45 \\
\hline 26. & Verampamil & 3 & 0.68 \\
\hline 27. & Furosemide & 25 & 5.72 \\
\hline 28. & Spironolactone & 10 & 2.28 \\
\hline 29. & Telmisartan & 10 & 2.28 \\
\hline & Total & & 437 \\
\hline
\end{tabular}

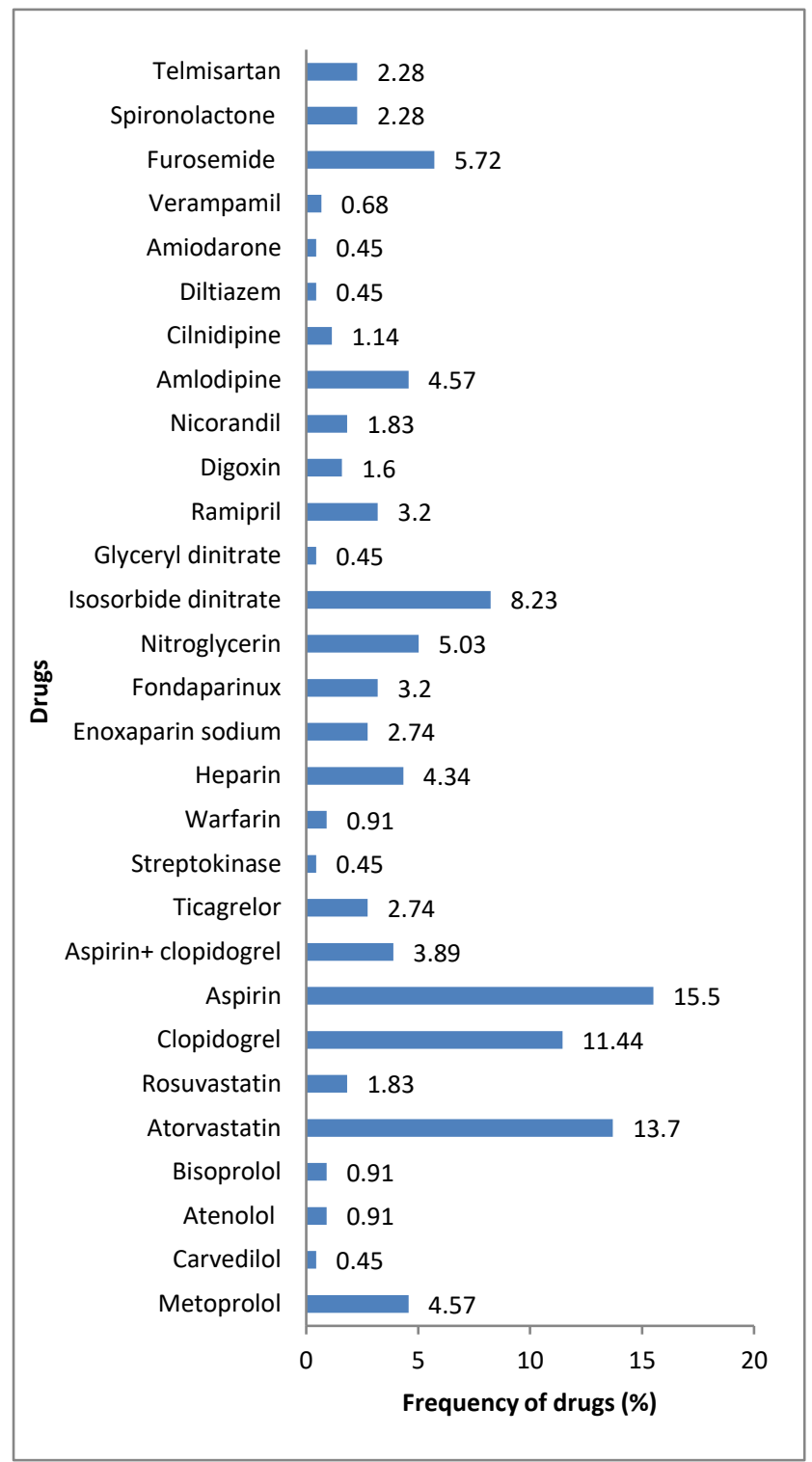

Figure 6: Utilization pattern of cardiovascular drugs

\section{Class wise utilization of non-cardiovascular drugs}

Other than cardiovascular drugs, antiulcers (31.19\%), antidiabetic drugs (15.13\%), antibiotics (12.38\%), anxiolytics $(10.1 \%)$, antiemetics $(10.1 \%)$, glucocorticoid (9.17\%), laxatives (6.88\%), analgesics $(5.04 \%)$ were also prescribed to the patients. Single agents were prescribed more than combinations (Table 5 and Figure 7).

Table 5: Utilization of non-cardiovascular class

\begin{tabular}{|c|c|c|c|}
\hline S. No. & Drug category & $\begin{array}{l}\text { Frequency of } \\
\text { prescription }\end{array}$ & $\begin{array}{c}\text { Percentage } \\
\text { (\%) }\end{array}$ \\
\hline 1. & Anxiolytics & 22 & 10.01 \\
\hline 2. & Anti-emetics & 22 & 10.01 \\
\hline 3. & Analgesics & 11 & 5.04 \\
\hline 4. & Anti-ulcers & 68 & 31.19 \\
\hline 5. & $\begin{array}{l}\text { Anti-diabetic } \\
\text { agents }\end{array}$ & 33 & 15.13 \\
\hline 6. & Laxatives & 15 & 6.88 \\
\hline 7. & Glucocorticoid & 20 & 9.17 \\
\hline 8. & Antibiotics & 27 & 12.38 \\
\hline & Total & \multicolumn{2}{|c|}{218} \\
\hline
\end{tabular}

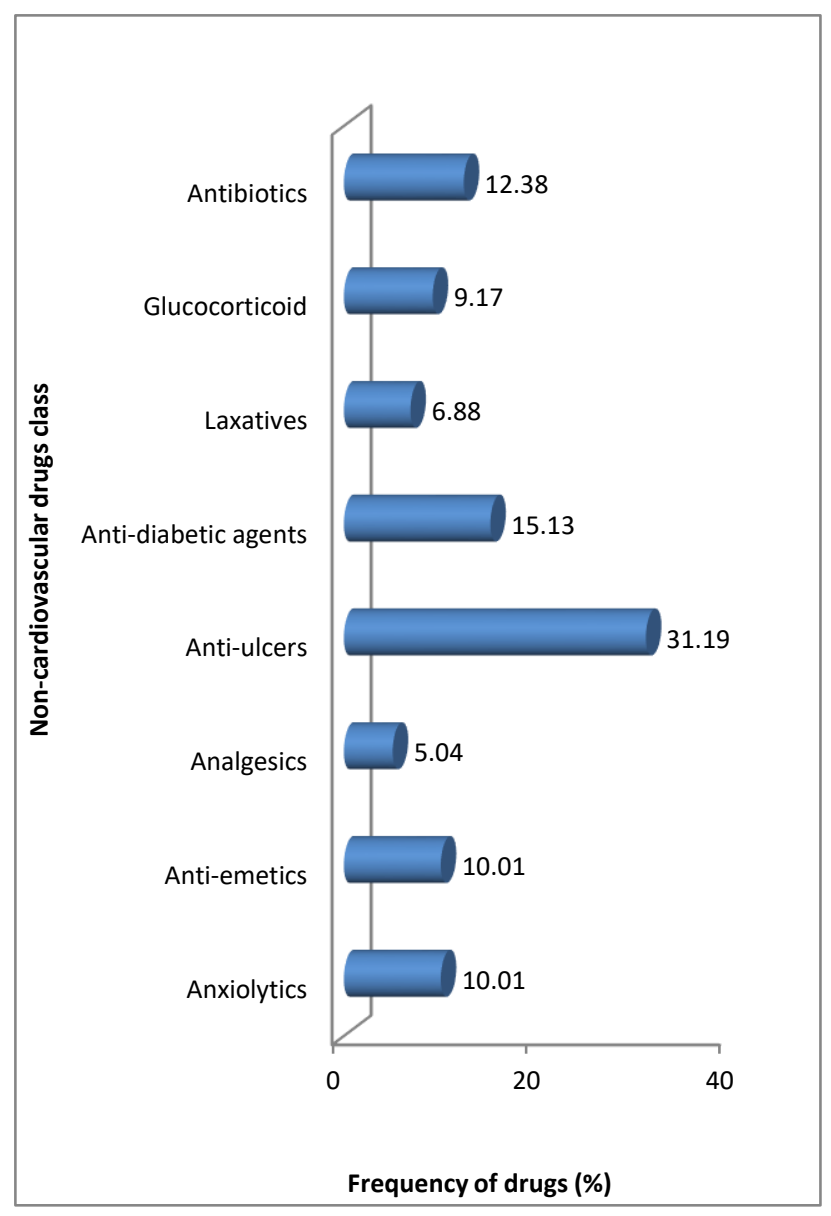

Figure 7: Utilization of non-cardiovascular class

\section{Prescriptions with non- cardiovascular drugs}

Table-6 shows that other than the cardiovascular drugs pantoprazole (27.52\%), hydrocortisone (9.17\%), metformin (6.88\%), alprazolam (6.88\%), domperidone 
(5.04\%), ondansetron (5.04\%), piperacillin + tazobactum $(4.58 \%)$, lactulose $(4.58 \%)$, cefoperazone+ sulbactum $(3.66 \%)$, metformin + glimepride $(3.66 \%)$, ranitidine (3.66\%) were mostly prescribed.

\section{Drug-drug interaction found in the cardiovascular emergencies}

Among the 100 cases collected, 200 DDls were identified and majority of potential DDIs were pharmacodynamic in nature. The drug pairs reported with highest frequency of drug-drug interactions were aspirin + clopidogrel (in 54 patients), pantoprazole + clopidogrel (in 45 patients), clopidogrel + atorvastatin (in 30 patients). The number of DDIs increased when the number of prescribed drugs increased (Table 7). Moderate DDIs (60\%) were found be more than the minor (7\%) and major (33\%) (Figure 8).

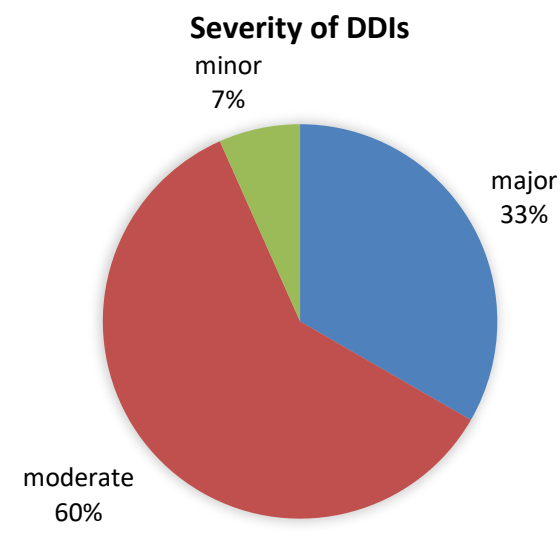

Figure 8: classification of DDIs according to their severity
Table 6: Non-cardiovascular drugs prescribed

\begin{tabular}{|c|c|c|c|}
\hline S. no. & Drug class & $\begin{array}{c}\text { Frequency } \\
\text { of } \\
\text { prescription }\end{array}$ & $\begin{array}{c}\text { Percentage } \\
\text { (\%) }\end{array}$ \\
\hline 1. & Alprazolam & 15 & 6.88 \\
\hline 2. & Levitracetam & 1 & 0.45 \\
\hline 3. & Piracetam & 2 & 0.91 \\
\hline 4. & Clonazepam & 4 & 1.83 \\
\hline 5. & Ondansetron & 11 & 5.04 \\
\hline 6. & Domperidone & 11 & 5.04 \\
\hline 7. & Diclofenac & 1 & 0.45 \\
\hline 8. & Tramadol & 5 & 2.29 \\
\hline 9. & Acetaminophen & 5 & 2.29 \\
\hline 10. & Pantoprazole & 60 & 27.52 \\
\hline 11. & Ranitidine & 8 & 3.66 \\
\hline 12. & Metformin & 15 & 6.88 \\
\hline 13. & Glimepride & 5 & 2.29 \\
\hline 14. & $\begin{array}{l}\text { Metformin+ } \\
\text { glimepride }\end{array}$ & 8 & 3.66 \\
\hline 15. & Regular insulin & 5 & 2.29 \\
\hline 16. & Lactulose & 10 & 4.58 \\
\hline 17. & Bisacodyl & 5 & 2.29 \\
\hline 18. & Hydrocortisone & 20 & 9.17 \\
\hline 19. & Piperacillin+tazobatum & 10 & 4.58 \\
\hline 20. & $\begin{array}{c}\text { Cefoperazone + } \\
\text { sulbactum }\end{array}$ & 8 & 3.66 \\
\hline 21. & Amikacin & 6 & 2.75 \\
\hline 22. & Ceftriaxone & 3 & 1.37 \\
\hline & Total & \multicolumn{2}{|c|}{218} \\
\hline
\end{tabular}

Table 7: DDIs found in the medication chart

\begin{tabular}{|c|c|c|c|}
\hline S. no. & DDIS & Effects & No. of patients \\
\hline 1 & Aspirin + clopidogrel & Increase the risk of bleeding & 54 \\
\hline 2 & Aspirin + metoprolol & Decrease antihypertensive effect & 12 \\
\hline 3 & Pantoprazole + clopidogrel & Increase risk of bleeding & 45 \\
\hline 4 & Furosemide + ramipril & Reduce blood pressure & 2 \\
\hline 5 & Furosemide + telmisartan & Alter serum potassium level & 2 \\
\hline 6 & Atorvastatin + clopidogrel & Decrease antiplatelet effect & 30 \\
\hline 7 & Aspirin + heparin & Increase the toxicity and risk of bleeding & 10 \\
\hline 8 & Aspirin + ramipril & Decrease antihypertensive efficacy & 12 \\
\hline 9 & Aspirin + fondaparinux & Increase bleeding and swelling & 7 \\
\hline 10 & Ramipril + metformin & Increase risk of hypoglycaemia & 3 \\
\hline 11 & Spironolactone + ramipril & Increase risk of hyperkalaemia & 2 \\
\hline 12 & Insulin + aspirin & Increase hypo/ hyperglycemia risk & 10 \\
\hline 13 & Digoxin + atenolol & Effect on potassium level by antagonism & 4 \\
\hline 14 & Enoxaparin + aspirin & Increases anticoagulation & 3 \\
\hline 15 & Verapamil + aspirin & Increase antiplatelet activity & 4 \\
\hline Total & & & 200 \\
\hline
\end{tabular}




\section{DISCUSSION}

In the last few decades, several research on the safety and efficacy of drugs have been performed all over the world. Drug utilization studies have proven to be a useful tool in overcoming inappropriate drug use and irrationality of drug patterns, as well as in maintaining the quality of life. The aim of this research was to look at the drug prescribing patterns in the cardiovascular disorders in a tertiary care hospital.

Total 100 patients were enrolled and the data were collected and analyzed. The results pointed out that the frequency of the cardiovascular events was more in male patients (65\%) as compared to female patients (35\%). These results were supported by the similar study conducted by Mukesh Kumar et al. and Zafar.F et al.in which $61 \%$ of cases were males and $39 \%$ were female. ${ }^{9,10}$

The incidence of CVDs was higher in the patients aged 6170 years ( 30 out of 100 ) followed by $51-60$ years ( 26 out of 100) which was in concordance to the study conducted by Shabbir Rafiq Pendhari et al. ${ }^{11}$

Majority of the patients stayed for less than 7 days (54\%), $(30 \%)$ of patients stayed for 7 days and less than (16\%) of patients stayed more than 7 days. These findings are in the accordance with Bandla Aswani et al. ${ }^{12}$

Our study shows that, the most common diagnosis was myocardial infarction (31\%) followed by angina, coronary artery disease and arrhythmia which shows similarity with studies ofSaranya et al. ${ }^{13}$

In our study, we noticed hypertension (45\%) and type 2 diabetes mellitus (33\%) as frequently associated comorbid conditions which was in concordance to the findings of Saranya et al.and Rohan et al. ${ }^{13,14}$

Out of total 655 drugs prescribed, 437 cardiovascular drugs were prescribed and the majorly prescribed category was anti-platelets 139 (31.80\%), anti-hyperlipidemic 68 (15.5\%), anticoagulants 49(11.21\%). Other than cardiovascular drugs, 218 other classes like antacids 68(31.19\%), anti-diabetic 33(15.13\%), antibiotics $27(12.18 \%)$ were prescribed. These results correlate with the study reported by Nilay Solanki et al showing the most commonly prescribed drugs in the same sequence. ${ }^{15}$

The report from our study states that the most common drugs used in CVE are aspirin 68 (15.5), atorvastatin 60 (13.7\%), pantoprazole 60 (27.52\%) followed by clopidogrel $50(11.44 \%)$. In the study conducted by Blessy Rachel et al, the prescribing frequency of aspirin and atorvastatin was majorly seen. ${ }^{16}$

Out of 100 patients, majority were of pharmacodynamic in nature followed by pharmacokinetic interactions. Level of major severity was found in aspirin + clopidogrel, pantoprazole+ clopidogrel, atorvastatin+ clopidogrel, aspirin + ramipril which was in accordance to the reports of Virendra k patelet.al and Kumar et.al. ${ }^{17,18}$

\section{CONCLUSION}

The present study reveals the higher prevalence of myocardial infarction and angina in male patients ofage group 61-70 years. Hypertension and DM were the most commonly associated co-morbidties. The use of antiplatelets and anticoagulants help in the effective treatment and prevention of most CVDs. The presence of polypharmacy leads to the occurrence of potential DDIs which increase the risk in CVD patients. So, targeted education in prescribers is required. Moreover, time to time studies is necessary for assessing the drug utilization pattern and improving the quality of life in patients.

\section{Limitation}

The study was limited to the in-patients so the generalized pattern of drug utilization in the institution could not be evaluated. Our study was retrospective so, interaction with the patients was not done and the patients were not followed after their discharge. Information about overthe-counter drugs was not included in the study.

\section{REFERENCES}

1. Naliganti C, Valupadas C, Akkinepally RR, Eesam S. Evaluation of drug utilization in cardiovascular disease at a teaching and referral hospital in Northern Telangana. Indian Journal of Pharmacology. 2019; 51(5): 323-329.

2. Kerkar SS, Bhandare PN. Study of utilisation trends of drugs in patients admitted with cardiovascular diseases at a tertiary care hospital in Goa. International Journal of Scientific Report. 2017; 3(12): 311-17.

3. Jyothi D, Kumar VS, Undrakonda A, Bhargavi $\mathrm{N}$ et.al. Assessment and Drug Utilization Pattern on Antiplatelet Agents in Cardiovascular Patients - A Prospective Study in Tertiary Care Hospital. International Journal of Pharmacy and Pharmaceutical Research. 2019; 14 (2): 109-119.

4. Fardan M, Manjari S, Periasamy S. Study of drug utilization in cardiovascular emergency at a rural teaching hospital in Tamilnadu, India. International Journal of Basic \& Clinical Pharmacology. 2019; 8(7): 1587-1593.

5. UV Mateti, T Rajakannan, H Nekkanti, V Rajesh et.al Drugdrug Interactions in Hospitalized Cardiac Patients. Journal of Young Pharmacists. 2009; 3(4): 329-333.

6. Sneha.C, Anuradha HV, Kulkarni SG. Assessment of drugdrug interactions in the prescription of elderly patients on cardiovascular drugs. International Journal of Basic \& Clinical Pharmacology.2019; 8(5): 1078 - 1082.

7. Murtaza G, Khan MYJ, Azhar S, Khan SA et.al. Assessment of potential drug-drug interactions and its associated factors in the hospitalized cardiac patients. Saudi Pharmaceutical Journal. 2016; 24(2): $220-225$.

8. Shanbhag AD, Hema NG, Sadananda KS. Potential drugdrug interactions among hospitalized cardiac patients. International Journal of Basic \& Clinical Pharmacology. 2016; 5(5): 2251-2256.

9. Kumar M, Dahiya V, Mishra S, Sharma D, Mishra $N$ et.al. Cardiovascular disease prevalence and drug utilization patterns at a tertiary care hospital in Northeastern India. 
International Journal of Pharmacy and Pharmaceutical Sciences. 2016; 8(6): 116-119.

10. Zafar F, Ali $\mathrm{H}$, Naveed S, Koral OU et.al. Drug utilization pattern in cardiovascular disease: A descriptive study in a tertiary care setting in Pakistan. Journal of Bioequivalence and bioavailability. 2015; 7(1): 26- 29.

11. Pendhari SR, Chaudhari DR, Burute SR, Bite BM. A study on the drug utilization trends in the cardiovascular emergencies in a tertiary care hospital. Journal of Clinical and Diagnostic Research. 2013; 7(4): 666-670.

12. Aswani B, Reddy PK, Yanadaiah P, Sujatha S. A study of prescribing pattern of cardiovascular drugs and potential drug drug interaction in an inpatient cardiology unit of a cardiac - care hospital at tirupathi. European Journal of Pharmaceutical and Medical Research. 2016; 3(8): 294 305.

13. Lakshmi SK, Gowda HN, Sadananda KS. A study of drug utilization trends in acute coronary syndrome in intensive cardiac care unit at a tertiary care hospital. International Journal of Basic \& Clinical Pharmacology. 2017; 6 (2): 344348.
14. Christian RP, Rana DA, Malhotra SD, Patel VJ. Evaluation of rationality in prescribing, adherence to treatment guidelines, and direct cost of treatment in intensive cardiac care unit: A prospective observational study. Indian Journal of Critical Care Medicine. 2014; 18(5): 278284.

15. Solanki N, Patel V, Patel R. Prescribing trends in Cardiovascular conditions:A prospective cross sectional study. Journal of basic and clinical pharmacy. 2019; 10(2): 23-26.

16. Thomas BR, Catherine TJ, Sabu N, Lekshmi ES et.al. Prescribing pattern of cardiovascular drugs- A prospective Observational Study. Indian Journal of Pharmacy Practice. 2017; 10(4): 287-292

17. Patel VK, Acharya LD, Rajakannan T, SurulivelrajanMet.al. Potential drug drug interactions in patients admitted in cardiology wards of a south Indian teaching hospital. Australasian Medical Journal. 2011; 4(1): 9-14.

18. Kumar US, Deepak P, Nalini GK, Prema M et.al. Potential Drug-Drug Interactions among Hospitalized ICU Patients. World Journal of Pharmaceutical and Medical Research. 2018; 4(2): 124-127.

Source of Support: None declared.

Conflict of Interest: None declared.

For any question relates to this article, please reach us at: editor@globalresearchonline.net New manuscripts for publication can be submitted at: submit@globalresearchonline.net and submit_ijpsrr@rediffmail.com 